\title{
COMMUNITY EXPERIENCES THROUGH PEER INTERACTION RITUALS OF A MONGOLIAN-KOREAN CHILD IN THE PRESCHOOL CLASSROOM
}

\author{
Gab-Jung Yoon ${ }^{1}$, \& Kai-Sook Chung ${ }^{2}$ \\ ${ }^{1}$ Department of Child Welfare, Daegu Haany University (South Korea) \\ ${ }^{2}$ Department of Early Childhood Education, Pusan National University (South Korea)
}

\begin{abstract}
The rituals contain symbolic meaning about the culture of the peer group. It is likely that rituals frequently indicate the inclusion or exclusion of specific individuals by the group. Currently South Korean society began to diversify with an increasing number of immigrants and their families, which calls for a more serious discussion on school adaptation of children from multicultural families. This study examined community experiences of a Mongolian-Korean child through peer interaction rituals over time in the preschool classroom, South Korea. The theoretical framework of this study is based on interaction ritual chain and multicultural education theory. The methodology consists of a qualitative case study approach. The research classroom is a 5 years of age class has 8 boys, 12 girls, and one teacher, which has one Mongolian-Korean boy and the others are Korean children. The data were gathered through classroom participant observations 3 hours a day, twice a week for 6 months and interview with a Mongolian-Korean boy, his Mongolian mother and teacher. The data were analyzed by conducting content and meaning analysis. In the research, a Mongolian-Korean child's community experiences were related to transition to group emotions, symbol, and memories over time. The results showed that 1) in the beginning of the semester, he used to ask for help from his teacher whenever he meets conflicts among friends and have often an angry expression during free paly time. But he has changed to share positive group emotions between friends through peer interaction rituals 2) in the beginning of the semester, he was interested in 'dinosaur', which was his private symbol and he didn't want to let friends know the information about it. But he has changed to explain dinosaur to his friends and 'dinosaur' has become the group symbol 3) in the beginning of the semester, he didn't say to friends about 'Mongol', which was just his mom's hometown and his private memories. But he has changed to introduce to friends about Mongol and 'Mongol' has become group memories as a common story after project activity. These results described peer interaction rituals that contribute to make a sense of community in preschool settings and offered suggestions for creating multicultural classroom community.
\end{abstract}

Keywords: Young children, peer interaction rituals, community, multicultural classroom, preschool.

\section{Introduction}

There are currently 141 million immigrants living in South Korea and $2.8 \%$ of the overall population. Multicultural families are 31 million 6 thousand households and the household consisted in a Korean father and immigrant mother make up 36.6\% of them. Young children from multicultural families make up 56.4\% of multicultural families (KOSIS, 2017). Young children from multicultural families are more likely than non-multicultural children have struggles of preschool adjustment in South Korea (Oh, 2011). They tend to show individual and alienated play to perception of surroundings, unconditional patience, observation, imitation, and interaction through paly with limited friends (Leem, 2013). So, many researches have examined their social development and peer interaction patterns in preschool (Kim \& Park, 2010; Lee, 2013; Park \& Lee, 2010), but little effort to focused on their community experiences through classroom rituals.

Rituals comprise symbolic actions that create social orders (Hallett, 2007) and ritual performances are expressed through everyday interactions (McLaren, 1987). Routines and rituals can be distinguished along three dimensions: communication, commitment, and continuity (Fiese, Tomcho, Douglas, Josephs, Poltrock, \& Baker, 2002). For example, during the mealtime, routine communications are typically direct and instrumental but ritual communication is symbolic. That is, the use of nicknames, inside jokes, and terms of endearment reinforce individuals' role in the group and hold meaning for those inside the family. 
And the commitment to routine is task oriented setting, clearing, washing dishes but ritual is affective and emotional. The continuity to routine focus on food time limited role repetition but ritual focus on group belonging, cross-generational symbolic referents, future planning.

In the interaction ritual chains theory, participants share interests through rituals and experience mutual subjectivity and emotional connection, finally they feel a strong sense of belonging (Collins, 2004). Collins (2004) argues that interaction rituals produce emotional energy, the gathering of which is a central motivating force for individuals. Affect is the engine of social order. Those interaction rituals that are most effective in generating emotional energy are the ones that bolster institutional stability.

Especially, children form their own rituals separately to adults, which may be evinced in paly and talk. The rituals contain symbolic meaning about the culture of the peer group. It is likely that rituals frequently indicate the inclusion or exclusion of specific individuals by the group (Kyratzis, 2004). Therefore, this study examines community experiences of a Mongolian-Korean child through peer interaction rituals over time in the preschool classroom, South Korea.

\section{Methods}

\subsection{Design}

This research was designed as a case study. The case study enables to obtain holistic and meaningful features about real-life events (Yin, 2009). The preschool has 99 children ranged from 2 years to 5 years and 17 teaching staffs, is located in G city, South Korea. The research classroom is a 5 years of age class which has 8 boys and 12 girls. The class has one Mongolian-Korean boy and the others are Korean children. Most of the children belonged to middle-income families, and the Mongolian-Korean boy's family has a Mongolian mother and a Korean father.

\subsection{Data collection}

Participant observation was carried out for 6 months (from April to October, 2018, except vacation), three hours each day, twice a week in the classroom. Observation was focused on Mongolian-Korean boy's narratives, behaviors, and face expression through peer interaction rituals during free play time, circle time, mealtime etc. And the semi-structured interviewed conducted with an assistant principal, a class teacher and a Mongolian mother of a participant boy. Also, class curriculum, school newsletter and a Mongolian-Korean boy's educational portfolio were collected.

\subsection{Data analysis}

In the data analysis process, observation data, interview data, printed documents and educational portfolio were brought together, and transcripts were constructed. Two step process was used in the analysis of the transcripts. In the first phase, the data set was content-analyzed in terms of peer interaction ritual's types and functions. In the second phase, meaning analysis was conducted in order to figure out the community experiences of a Mongolian-Korean boy.

\section{Results}

A Mongolian-Korean child's (assumed name: JUNHO) experiences of community were related to transition to group emotions, symbol, and memories over time through peer interaction rituals. Classroom rituals were included in 'monday morning prayer', 'everyday luxury greeting', 'listening attitude chant in the circle time', 'thankful chant before lunch', 'taking a group picture in the peer birthday party', 'peer interaction signs to gather peers and start off play.'

\subsection{Transition from negative emotions to positive emotions}

In the beginning of the semester, he used to ask for help from his teacher whenever he meets conflicts among friends and have often an angry expression during free paly time. But he has changed to share positive group emotions(smile, laugh, shout) between friends through peer interaction rituals. In the interaction ritual contexts, a good example for making group emotion is 'sharing of laughter' and laughter is likely to 'repeat rhythm'(Collins, 2004). At the end of the semester, Junho laughed frequently and played with his friends joyfully. 
3.1.1. The beginning of the semester: looking at his teacher with a tearful face. 5 boys are playing top-spinning game in their classroom

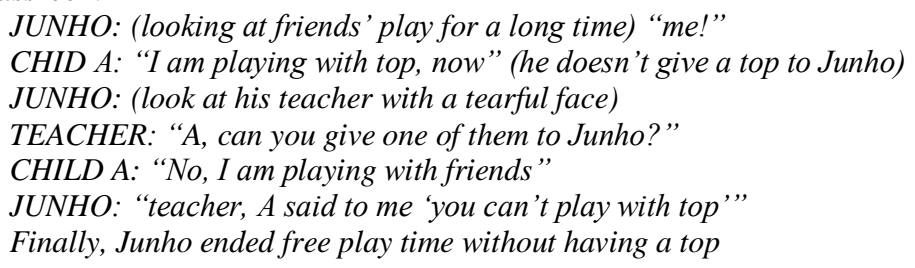

3.1.2. The end of the semester: playing with his friends joyfully. 5 children play hide-and-seek outside

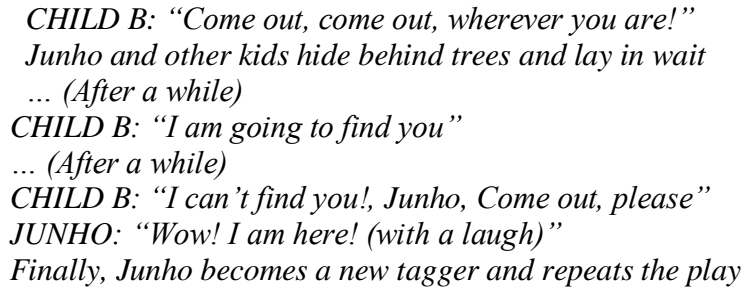

\subsection{Transition from his private symbol to the group symbol, 'dinosaur'}

In the beginning of the semester, he was interested in 'dinosaur', which was his private symbol and he didn't want to let friends know the information about it. But he has changed to explain dinosaur to his friends and 'dinosaur' became the group symbol. As well as actions and interactions, rituals are also associated with symbolic objects. Symbolic objects communicate ideas, values or attitude among children (Maloney, 2000).

3.2.1. The beginning of the semester: private interest in different types of dinosaur. At the snack time

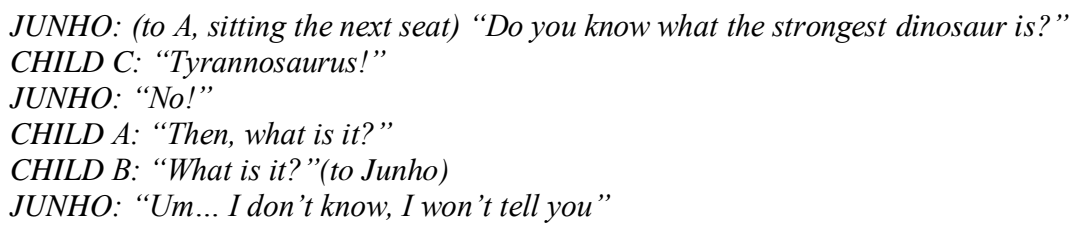

3.2.2. The end of the semester: giving his dinosaur's information to his friends. CHILD A: (to me) "Teacher, do you know 'Nanotyrannus'?"

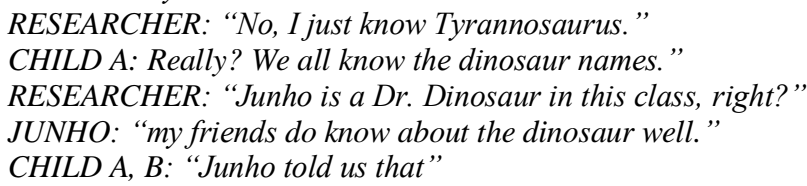

\subsection{Transition from his mom's hometown to group memory and story, 'Mongol'}

In the beginning of the semester, he didn't say to friends about 'Mongol' voluntarily, which was just his mom's hometown and his private memories. But he has changed to introduce to friends about Mongol and 'Mongol' has become group memories as a common story after 'bank' project activity. In the ritual theory, group stories could make common emotions and memory finally, they could experience sense of community (Wulf, 2013).

3.3.1. The beginning of the semester: Mongol is his mom's hometown. JUNHO: "my mom's hometown is Mongol, did you know that?"

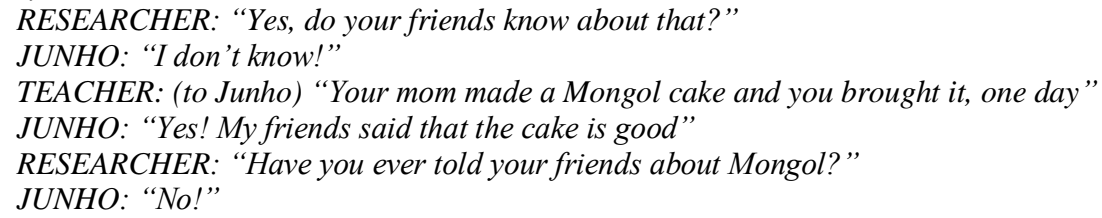


3.3.2. The end of the semester: talking about his experiences in Mongol to his friends. TEACHER: When we had a 'bank' project activity, Junho was in Mongol with his parents.

So, I asked his mother for taking picture of Mongol's bank and money.

She posted Mongol bank and money pictures in class online café.

I and children could talk about Mongol's bank in the project time.

After Junho came back to Korea,

We had a circle time and he said his experiences in Mongol to his friends. After that, children became interested in the Mongol.

They often ask to Junho Mongol's house, foods, play, his relatives living in there etc. Some kids said to me 'I want to go Mongol later"

\section{Conclusions}

These results showed that a Mongolian-Korean child's adjustment and experiences of community through peer interaction rituals which are evinced in paly and talk over time. It described peer interaction rituals that contribute to make a sense of community in preschool settings. And it showed that the experiences of community were related to share to group emotions, symbol, and memories. The findings suggest that further studies on peer interaction ritual's roles for creating multicultural classroom community.

\section{References}

Collins, R. (2004). Interaction ritual chains. Princeton. NJ: Princeton University Press.

Fiese, B. H., Tomcho, T., Douglas, M. Josephs, K., Poltrock, S., \& Baker, T. (2002). Fifty years of research on naturally occurring rituals: Cause for celebration? Journal of Family Psychology, 16, 381-390.

Hallett, T. (2007). Between deference and distinction: Interaction ritual through symbolic power in an educational institution. Social Psychology Quarterly, 70(2), 148-171.

Kim, H-K., \& Park, M-S. (2010). A study on the relationship of peers and teachers of young children of the multicultural families. Journal of Multicultural Education, 3(1), 88-104.

KOSIS (Korean Statistical Information Service). (2017). Statistics to see easily: Population, household, and hosing-cities and countries. Retrieved January 5, 2018, from http://kosis.kr/easyViewStatis/customStatisIndex.do?vwcd=MT_TM2_TITLE\&menuId=M_03_02

Kyratzis, A. (2004). Talk and interaction among children and the co-construction of peer groups and peer culture. Annual Review of Anthropology, 33, 625-649.

Lee, H. W. (2013). A study on developing social competence improvement program and its effect on children from multicultural family. Journal of Early Childhood Education \& Educare Welfare, 17(2), 216-234.

Leem, H-H. (2013). A case study of the adjustment process of young children from multi-cultural families at daycare centers. Unpublished master's dissertation, Sookmyung Women's University.

Maloney, C. (2000). The role of ritual in preschool setting. Early Childhood Education Journal, 27(3), 143-150.

McLaren, P. (1987). The anthropological roots of pedagogy: the teacher as liminal servant. Anthropology and Humanism Quarterly, 12(3\&4), 75-85.

Oh, Y-H. (2011). Analysis on conflict in play situations of infant from multicultural families. Journal of Early Childhood Education \& Educare Welfare, 15(1), 39-58.

Park, M. J., \& Lee, B. I. (2010). The grounded theory on the adaptational process and interaction-behavioral types of young children with multicultural families. Journal of Special Education, 45(1), 129-151.

Wulf, C. (2013). Anthropology: A continental perspective. Translated by Winter, D., Margitta, E. H., \& Rouse, R. L. Chicago, IL: The University of Chicago Press. Originally published as Anthropologie: Geschichte Kultur Philosophie in 2004.

Yin, R. K. (2009). Case study research: Design and methods. Sage Publications. 